\title{
Industrial Trial Standard Cancer Center Information Summary
}

National Cancer Institute

\section{Source}

National Cancer Institute. Industrial Trial Standard Cancer Center Information Summary.

NCI Thesaurus. Code C39428.

The Industrial Trial, Standard Cancer Center Information Summary for Cancer Center Support Grant Application, is a clinical study which design and implementation is controlled by the pharmaceutical company. 